\title{
Effect of reproductive status on the diet composition of wolverines (Gulo gulo) in boreal forests of eastern Finland
}

\author{
Anni Koskela ${ }^{1, *}$, Ilpo Kojola², Jouni Aspi ${ }^{1}$ \& Marja Hyvärinen ${ }^{1}$ \\ 1) Department of Biology, P.O. Box 3000, Fl-90014 University of Oulu, Finland (*corresponding \\ author's e-mail: anni.koskela@oulu.fi) \\ 2) Finnish Game and Fisheries Research Institute, P.O. Box 413, Fl-90014 University of Oulu, \\ Finland
}

Received 6 July 2012, final version received 22 Nov. 2012, accepted 5 Dec. 2012

Koskela, A., Kojola, I., Aspi, J. \& Hyvärinen, M. 2013: Effect of reproductive status on the diet composition of wolverines (Gulo gulo) in boreal forests of eastern Finland. - Ann. Zool. Fennici 50: 100-106.

\begin{abstract}
Sex differences in foraging ecology have been found in a variety of taxa. We tested the hypothesis that breeding female wolverines (Gulo gulo), probably due to their smaller home ranges and higher energy demands because of gestation and lactation, are forced to rely more on food caches and carrion than other wolverines. The diet composition, as the percentage occurrence, was estimated for four breeding females and six males and non-breeding females by analyzing scat samples, all collected in eastern Finland. The most important food source for breeding female wolverines was human- and wolfkilled moose (55\%), while the diet also comprised mountain hare (13\%), domestic pig $(13 \%)$ and grouse $(11 \%)$. Mountain hare $(52 \%)$ was the most utilized food source for males and non-breeding females. Moose (22\%) and grouse (15\%) were also important components of the diet. Our study highlights the importance of human- and wolf-killed carrion for breeding female wolverines in areas where the density of medium-sized ungulates is low.
\end{abstract}

\section{Introduction}

Optimal foraging theory refers to a collection of models of feeding behaviour that assume that the foraging strategy should maximize fitness benefits related to costs, for example by minimizing the energy and time spent acquiring adequate nutrition (Pyke et al. 1977, Hughes 1980, Pyke 1984). The divergent life histories of different sexes in many species require the differential use of food and other resources, which could lead to sexspecific foraging behaviour (Dunbar 1988). Sex differences in foraging ecology have indeed been found in a variety of taxa (e.g. Ligon 1968, Clutton-Brock et al. 1983, Jormalainen et al. 2001).

Three different hypotheses have been suggested to explain sex differences in foraging ecology (Beck et al. 2003). First, the sexual sizedimorphism hypothesis is based on the fact that larger individuals require more energy per unit time than smaller ones, and therefore the larger sex may forage differently from the smaller sex (Nagy 1987). The larger sex may either consume more of the same foods eaten by the smaller 
sex or consume different food sources (CluttonBrock et al. 1987).

Second, the reproductive decisions hypothesis refers to the different parental duties of males and females. Each sex faces different trade-offs between foraging and other activities (provisioning of young, predator avoidance, mate acquisition) when maximizing individual fitness, which may cause sex differences in foraging behaviour (Clutton-Brock \& Parker 1992, Jormalainen et al. 2001). Female fitness, measured as reproductive success, is dependent on the nutritional status due to the high metabolic costs associated with gestation and lactation (Lee 1987). Male fitness, in contrast, often increases with the number of copulations that they can obtain (Arnquist \& Nilsson 2000). Therefore, the life history of females should maximize feeding efficiency, whilst males are expected to maximize their access to females (Sterck et al. 1997). Finally, the niche divergence hypothesis is based on the fitness benefit of reducing intraspecific competition by each sex foraging in different locations or on different prey species, or both (Schoener 1970, Clarke et al. 1998).

Wolverines (Gulo gulo) are sexually dimorphic mustelid species. Males are 30\% heavier and 10\% longer than females (Banci 1982, Pasitschniak-Arts \& Larivière 1995). The sexes also differ in their home-range size (Whitman et al. 1986, Banci \& Harestad 1990, Copeland 1996, Landa et al. 1998, Dawson et al. 2010). The area used by non-breeding females and adult males varies from 200 to $1500 \mathrm{~km}^{2}$. Females with cubs usually utilize the smallest home ranges, varying from 40 to $100 \mathrm{~km}^{2}$. Wolverines are solitary, like most mustelids. Female wolverines give birth before late March, the average litter size being 2-3 cubs. The young are weaned at 9-10 weeks and they begin to travel with their mother by late April.

Wolverines hunt and scavenge for food (Magoun 1987). Due to sexual size dimorphism and differences in home-range size and parental duties, wolverines might exhibit sex-specific foraging behaviour. However, quantitative information is lacking, with a few exceptions in North America (Lofroth et al. 2007) and southern Norway (van Dijk et al. 2008b) in localities with a high density of medium-sized ungulates.
The Finnish wolverine population has a bipartite distribution. Approximately $50 \%$ of the 155-170 Finnish wolverines are found in northern Finland (Heikkinen \& Kojola 2010), where the semi-domesticated reindeer (Rangifer tarandus tarandus) is most probably their primary prey, as in Scandinavia (cf. Myhre \& Myrberget 1975, Landa et al. 1997, Mattisson et al. 2011). The other half of the population is distributed south of the reindeer management area, in eastern and central Finland, in habitats with a very low density of medium-sized ungulates (wild forest reindeer; Rangifer tarandus fennicus). Instead of hunting them, wolverines probably have to rely more on carrion (e.g. wolf-killed moose; Alces alces), and hunt smallsized prey items, such as mountain hares (Lepus timidus), grouse (Tetraonidae) and small rodents (Cricetidae).

In this study, we examined the dietary habits of wolverines in eastern Finland by comparing the diet composition of breeding females with that of males and non-breeding females. We collected scat samples from den sites and by tracking wolverines, and tested the hypothesis that breeding females, due to their more restricted home ranges and higher energy demands because of gestation and lactation, are forced to rely more on food caches and carrion than males and nonbreeding females.

\section{Material and methods}

Our study area is located in eastern Finland (Fig. 1) in an approximate area of $11160 \mathrm{~km}^{2}$. The topography is flat, with the altitude varying mainly from 160 to $340 \mathrm{~m}$ a.s.l. This area belongs to the mid-boreal coniferous forest zone and has a mildly continental climate (Ahti et al. 1968). The mean annual temperature is $2{ }^{\circ} \mathrm{C}$ and the mean annual precipitation $600 \mathrm{~mm}$. The ground is usually snow-covered from November to April. The landscape is mainly comprised of boreal forests, lakes and mires. About $80 \%$ of the land area is covered by forests, the dominant tree species being Scots pine (Pinus sylvestris) and Norway spruce (Picea abies). Extensive forest harvesting has occurred in the study area, and young mixed forests are common. Altogether, 


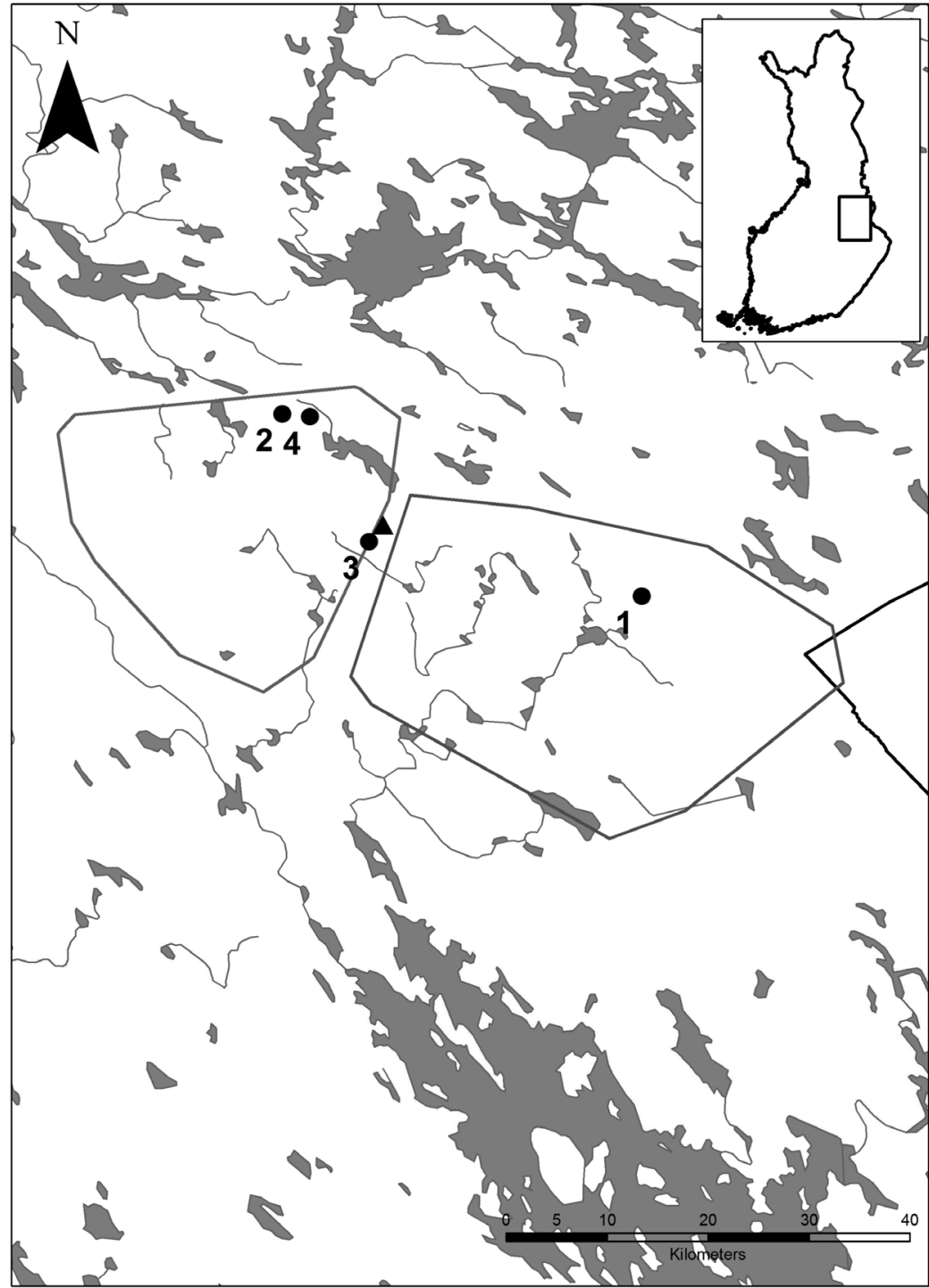

Fig. 1. Study area in Finland. Black dots represent the nests of breeding female wolverines (1-4) and a black triangle in the eastern study area represents the feeding site. The two wolf territories in the study area are indicated with a solid line. Males and non-breeding females were also all located inside the two wolf territories.
$1.8 \%$ of the study area is protected. The average density of humans in the study area is five people per $\mathrm{km}^{2}$. Human infrastructure is mainly constrained near to town centres, but many people have holiday cottages outside these areas.

The estimated wolverine population in eastern Finland is 50-60 individuals, the total population of Finland being at least 155-170 individuals. The population is stable or slightly increasing (Landa et al. 2000). Wild forest reindeer exists in the study area at a very low mean density $\left(0.1-0.2\right.$ per $\left.\mathrm{km}^{2}\right)$ and moose at a low density (0.3-0.5 per $\mathrm{km}^{2}$ ) (Wikman 2010). Other potential prey species include grouse, moun- tain hares and small rodents. Grey wolf (Canis lupus), brown bear (Ursus arctos) and Eurasian lynx (Lynx lynx) are the large predators that occur in the study area.

We examined wolverine dietary habits by analyzing the contents of scats. Scats representing the winter diet of breeding females $(n=168)$ were collected from four wolverine den sites located in eastern Finland during 2004-2006. Scat collection took place after the denning period in spring, when the female wolverines and cubs had left their dens. Scats representing the diet of males and non-breeding females (n =64) were collected by tracking six wolverine 
individuals in eastern Finland during 2009-2011. The scats were from the winter season, and by tracking these animals for long enough we could determine that these scats did not belong to breeding females. Wolverines were tracked with the help of snow tracks. The tracks were found by searching potential areas and with the help of local people. Fresh tracks were only backtracked to avoid disturbing the wolverines. All of the wolverine scats found along the tracks were collected. We also recorded all the carcasses found along the tracks.

Collected scats were frozen and analyzed at the University of Oulu. Before handling, frozen scats were placed in a freezer for 24 hours at $-80{ }^{\circ} \mathrm{C}$ to destroy possible endoparasite eggs. A small portion of each scat sample was separated for DNA analysis, resulting in individual identification and sex determination when DNA was extracted successfully. Each scat sample was washed in a $0.5 \mathrm{~mm}$ sieve under running water. The remains (hairs, feathers, bones, plant material, non-food items) were oven-dried at $80{ }^{\circ} \mathrm{C}$ for 24 hours. Hairs and feathers were identified to the species level using macroscopic and microscopic characteristics (Debrot et al. 1982, Teerink 1991, De Marinis \& Asprea 2006) and a reference collection. Scats were divided into two groups: those produced by (1) breeding females and (2) males and non-breeding females. The percentage occurrence of the prey species in scats was calculated for both groups. This has been found to be the most appropriate method for wolverine diet studies (van Dijk et al. 2007). It indicates how common a prey species is in the diet and accounts for various prey species being found in a scat.

The occurrence of moose, mountain hare and grouse in the diet was assessed using logistic mixed-effects models with the reproductive status as a fixed covariate and the individual as a random factor using SYSTAT ver. 13 (SYSTAT Inc., Evanston, Illinois). The diet breadth for both groups was calculated using the standardized Smith's measure of niche breadth, FT, with the following equation:

$$
\mathrm{FT}=\sum \sqrt{p_{j} a_{j}},
$$

where FT is Smith's measure of niche breadth, $p_{j}$ is the proportion of individuals found in resource state $j\left(\Sigma p_{j}=1.0\right)$, and $a_{j}$ is the proportion of resource $j$ is of the total resources $\left(\Sigma a_{j}=1.0\right)$ (Smith 1982).

The 95\% confidence intervals were calculated using the equation:

$$
\sin \left[\arcsin (\mathrm{FT}) \pm \frac{1.96}{2 \sqrt{N}}\right],
$$

where $N$ is the total number of individuals studied.

\section{Results}

On the basis of scats, the most important food source for breeding female wolverines was moose $(55 \%$ of the diet; Table 1$)$. Mountain hare (13\%), domestic pig (13\%) and grouse (11\%) also appeared to be important food items. Small amounts of small rodents, beavers (Castoridae), raccoon dogs (Nyctereutes procyonoides), mustelids, other bird species, bird eggs, frogs, common lizards (Zootoca vivipara) and berries were also found in the scats. On the other hand, for males and non-breeding females, mountain hare (52\%) appeared to be the most utilized food item. Moose $(22 \%)$ and grouse (15\%) were also important components of their diet. Small quantities of wild forest reindeers, raccoon dogs, red foxes (Vulpes vulpes), other bird species, bird eggs and berries were also found in their scats. Carcasses found along the tracks of male and non-breeding female wolverines gave a similar picture (Table 2) to the scats. Among these, mountain hare was also the most common food item (38\%), followed by grouse $(31 \%)$ and moose $(21 \%)$.

The diet of breeding females included less mountain hare $\left(F_{1,229}=16.199, p<0.001\right)$ than that of males and non-breeding females. The occurrence of moose $\left(F_{1.229}=0.082, p=0.775\right)$ and grouse $\left(F_{1.229}=0.232, p=0.631\right)$ did not differ between the groups. Smith's measure of niche breadth did not suggest a difference in niche breadth between the groups (Table 1).

\section{Discussion}

As expected, analysis of the diet composition demonstrated an important role of carrion in 
Table 1. Percentage occurrence of different prey species found in wolverine scats. The final rows give the Smith's measure of niche breadth and confidence intervals $(95 \%) . f=$ female, $m=$ male.

\begin{tabular}{|c|c|c|c|c|c|c|c|c|c|c|c|c|}
\hline & \multicolumn{5}{|c|}{ Breeding females } & \multicolumn{7}{|c|}{ Males and non-breeding females } \\
\hline & All & 1 & 2 & 3 & 4 & All & 5 & 6 & 7 & 8 & 9 & 10 \\
\hline Moose & 55.2 & 81.4 & 69.7 & 17.2 & 61.5 & 22.0 & 35.7 & 15.0 & 12.6 & 92.5 & 0 & 0 \\
\hline Wild forest reindeer & 0 & 0 & 0 & 0 & 0 & 3.3 & 0 & 5.5 & 5.3 & 0 & 0 & 0 \\
\hline Domestic pig & 13.4 & 0 & 0 & 52.3 & 1.4 & 0 & 0 & 0 & 0 & 0 & 0 & 0 \\
\hline Mountain hare & 12.7 & 8.2 & 12.6 & 16.1 & 12.5 & 51.9 & 35.7 & 69.0 & 60.0 & 0 & 0 & 75.0 \\
\hline Rodents & 2.3 & 5.4 & 4.3 & 0 & 1.5 & 0 & 0 & 0 & 0 & 0 & 0 & 0 \\
\hline Grouse & 11.0 & 3.8 & 5.3 & 4.0 & 20.0 & 14.8 & 21.4 & 5.5 & 21.6 & 7.5 & 33.3 & 0 \\
\hline Beavers & 1.4 & 0 & 4.8 & 1.5 & 0.3 & 0 & 0 & 0 & 0 & 0 & 0 & 0 \\
\hline Pine marten & 1.3 & 0 & 0 & 4.4 & 0.4 & 0 & 0 & 0 & 0 & 0 & 0 & 0 \\
\hline Raccoon dog & 1.4 & 0 & 3.2 & 0 & 2.0 & 3.1 & 7.1 & 5.0 & 0 & 0 & 0 & 0 \\
\hline Red fox & 0 & 0 & 0 & 0 & 0 & 3.1 & 0 & 0 & 0 & 0 & 66.7 & 0 \\
\hline Other & 1.4 & 1.2 & 0 & 4.5 & 0.4 & 1.7 & 0 & 0 & 0.5 & 0 & 0 & 25.0 \\
\hline Number of scats & 168 & 25 & 31 & 41 & 71 & 64 & 14 & 20 & 19 & 4 & 3 & 4 \\
\hline Sex & $f$ & $f$ & $f$ & $f$ & $f$ & $\mathbf{f}, \mathbf{m}$ & $\mathrm{f}$ & $\mathrm{m}$ & $\mathrm{m}$ & $f$ & $\mathrm{~m}$ & $f$ \\
\hline Niche breadth & 0.763 & & & & & 0.68 & & & & & & \\
\hline $95 \% \mathrm{Cl}$ & $0.37-0.98$ & & & & & $0.40-0.88$ & & & & & & \\
\hline
\end{tabular}

the diet of breeding female wolverines. Moose and domestic pig, which are assumed to be mainly utilized as carrion, formed almost $70 \%$ of their diet. In northern Finland, semi-domesticated reindeer is the most important food source for wolverines. In eastern Finland, with a very low density of medium-sized ungulates, breeding female wolverines are forced to rely more on carcasses when they are available. The result concurs with the findings of van Dijk et al. (2008b), who found that female wolverines in Norway use the highly available moose carrion opportunistically and hunt less on small prey than males.

Wolverines are known to utilize both humanand wolf-killed moose. Remains from hunter harvests formed the largest single food source for scavengers in Scandinavia (Wikenros 2011). Caching behaviour is a significant part of wolverine foraging ecology (Samelius et al. 2002, Wright \& Ernst 2004), and therefore wolverines benefit from carrion for a long time after carcasses are found. Thus, remains from moose hunting can benefit female wolverines during the breeding season.

Wolf-killed moose might be an important food source for breeding female wolverines in eastern Finland, because it's available more frequently than remains from moose hunting. Wikenros (2011) found that the number of visits by scavengers to wolf-killed moose was highest during the spring when most scavengers rear their young. To increase their scavenging opportunities, wolverines probably tend to live in the same regions with wolves because of the higher availability of carrion, but not in very close proximity to them in order to avoid intra-guild predation (White et al. 2002). However, van Dijk et al. (2008a) found no evidence for the importance of direct intra-guild interactions for wolverines to localize food, and it seemed that wolverines actively avoided close contact with wolves. In Norway, the presence of bears, wolves and lynx was generally associated with forested areas at lower elevations, whereas wolverines selected rugged terrain at higher elevations (May et al. 2008).

Domestic pig in the breeding wolverine diet was obviously obtained during visits to feeding sites. The feeding of large carnivores for photo-

Table 2. Carcasses found by tracking male and nonbreeding female wolverines.

\begin{tabular}{lr}
\hline Food item & Percentage \\
\hline Mountain hare & 37.9 \\
Grouse & 31.0 \\
Moose & 20.7 \\
Wild forest reindeer & 6.9 \\
Other bird species & 3.4
\end{tabular}


graphic and recreational purposes is a common practice in east-central Finland.

Landa et al. (1997) suggested that the abundance of small rodents may be essential for wolverine kit survival in southern Norway. In our study, only $2.3 \%$ of the diet of females with cubs consisted of rodents, and males and non-breeding females did not utilize rodents at all in their diet. Voles in northern Europe have been shown to exhibit cyclic population dynamics. The length of the vole population cycle is reported to be 3-5 years, with generally synchronous fluctuations in different vole species (Hansson \& Henttonen 1985, 1988). During 2004-2006, when the scats of breeding females were collected for this study, vole densities were very low in eastern Finland (Huitu et al. 2009). Therefore, during high vole densities, breeding female wolverines may utilize more small rodents than during our study period. Males and non-breeding females probably do not prey very intensively on rodents, even during high vole density years, due to their larger home ranges and better foraging possibilities.

Based on the scat samples, the most utilized food item for males and non-breeding females was the mountain hare, and mountain hare remains were also the most common carrion that we observed when tracking these wolverines. Hunting small prey such as mountain hare or grouse might incur greater energetic costs than scavenging, but searching for carcasses takes more time. The larger home ranges and greater mobility of male wolverines probably enable them to more frequently come into contact with smaller prey than females.

In conclusion, our study highlights the importance of human- and wolf-killed carrion for breeding female wolverines in areas with a low density of medium-sized ungulates. Temporal and spatial variation in the availability of prey species and the occurrence of other predators, especially wolves, can have a major effect on wolverine population dynamics in boreal forest areas in Finland.

\section{Acknowledgements}

We wish to thank the many field staff who collected samples for our studies, especially the personnel of the Finnish Game and Fisheries Research Institute and Zoological museum of the University of Oulu. We also thank the many field technicians who assisted in this project, Seppo Ronkainen in particular. Anni Koskela was personally funded by the Jenny and Antti Wihuri Foundation and Suomen Luonnonsuojelun Säätiö.

\section{References}

Ahti, T., Hämet-Ahti, L. \& Jalas, J. 1968: Vegetation zones and their sections in northwestern Europe. - Annales Botanici Fennici 5: 169-211.

Arnqvist, G. \& Nilsson, T. 2000: The evolution of polyandry: multiple mating and female fitness in insects. - Animal Behaviour 60: 145-164.

Banci, V. 1982: The wolverine in British Columbia: distribution, methods of determining age and status of (Gulo gulo vancouverensis). - IWIFR-15, Ministries of Environment and Forests, Victoria, BC.

Banci, V. \& Harestad, A. S. 1990: Home range and habitat use of wolverines Gulo gulo in Yukon, Canada. - Holarctic Ecology 13: 195-200.

Beck, C. A., Boven, W. D., McMillan, J. I. \& Iverson, S. J. 2003: Sex differences in the diving behaviour of a size-dimorphic capital breeder: the grey seal. - Animal Behaviour 66: 777-879.

Clarke, J., Manly, B., Kerry, K., Gardner, H., Franchi, E., Corsolini, S. \& Focardi, S. 1998: Sex differences in Adelie penguin foraging strategies. - Polar Biology 20: 248-258.

Clutton-Brock, T. H., Guinness, F. E. \& Albon, S. D. 1983: The costs of reproduction to red deer hinds. - Journal of Animal Ecology 52: 367-383.

Clutton-Brock, T. H., Iason, G. R. \& Guiness, F. E. 1987: Sexual segregation and density related changes in the habitat use in male and female red deer. - Journal of Zoology (London) 211: 275-289.

Clutton-Brock, T. H. \& Parker, G. A. 1992: Potential reproductive rates and the operation of sexual selection. Quarterly Review of Biology 67: 437-456.

Copeland, J. P. 1996: Biology of the wolverine in Central Idaho. - M.Sc. thesis, University of Idaho, Moscow, Idaho, USA.

Dawson, F. N., Magoun, A. J., Bowman, J. \& Ray, J. C. 2010: Wolverine, Gulo gulo, home range size and denning habitat in lowland boreal forest in Ontario. Canadian Field-Naturalist 124: 139-144.

Debrot, S., Fivaz, G., Mermod, C. \& Weber, J. M. 1982: Atlas des poils mammifères d'Europe. - Institut de Zoologie, Université de Neuchâtel, Switzerland.

De Marinis, A. M. \& Asprea, A. 2006: Hair identification key of wild and domestic ungulates from southern Europe. - Wildlife Biology 12: 305-320.

Dunbar, R. I. M. 1988: Primate social system. - Croom Helm, London.

Franzreb, K. E. 1984: Foraging habits of the ruby-crowned and golden-crowned kinglets in an Arizona montane 
forest. - Condor 86: 139-145.

Hansson, L. \& Henttonen, H. 1985: Gradients in density variations of small rodents: the importance of latitude and snow cover. - Oecologia 67: 394-402.

Hansson, L. \& Henttonen, H. 1988: Rodent dynamics as community processes. - Trends in Ecology \& Evolution 3: $195-200$.

Heikkinen, S. \& Kojola, I. 2010: Suurpetojen lukumäärä ja lisääntyminen vuonna 2009. - In: Wikman, M. (ed.), Riistakannat 2010, Riistaseurantojen tulokset: 16-21. Finnish Game and Fisheries Research Institute, Helsinki.

Hofer, U., Baur, H. \& Bersier, L.-F. 2003: Ecology of three sympatric species of the genus Chamaeleo in a tropical upland forest in Cameroon. - Journal of Herpetology 37: 203-207.

Hughes, R. N. 1980: Optimal foraging theory in the marine context. - Oceanography and Marine Biology: Annual Review 18: 423-481.

Huitu, O., Kiljunen, N., Korpimäki, E., Koskela, E., Mappes, T., Pietiäinen, H., Pöysä, H. \& Henttonen, H. 2009: Density-dependent vole damage in silviculture and associated economic losses at a nationwide scale. - Forest Ecology and Management 258: 1219-1224.

Jormalainen, V., Honkanen, T., Makinen, A., Hemmi, A. \& Vesakoski, O. 2001: Why does herbivore sex matter? Sexual differences in utilization of Fucus vesiculosus by the isopod Idotea baltica. - Oikos 93: 77-86.

Krebs, C. J. 1999: Ecological methodology. - Benjamin Cummings, California.

Landa, A., Lindén, M. \& Kojola, I. 2000: Action plan for the conservation of wolverines (Gulo gulo) in Europe. - Nature and Environment 115, Council of Europe Publishing.

Landa, A., Strand, O., Linnell, J. D. C. \& Skogland, T. 1998: Home-range sizes and altitude selection for arctic foxes and wolverines in an alpine environment. - Canadian Journal of Zoology 76: 448-457.

Landa, A., Strand, O., Swenson, J. E. \& Skogland, T. 1997: Wolverines and their prey in southern Norway. - Canadian Journal of Zoology 75: 1292-1299.

Lee, P. C. 1987: Nutrition, fertility and maternal investment in primates. - Journal of Zoology 213: 409-422.

Ligon, J. D. 1968: Sexual differences in foraging behaviour in two species of Dendrocopos woodpeckers. - Auk 85: 203-215.

Lofroth, E. C., Krebs, J. A., Harrower, W. L. \& Lewis, D. 2007: Food habits of wolverine Gulo gulo in montane ecosystems of British Columbia, Canada. - Wildlife Biology 13: 31-37.

Magoun, A. J. 1987: Summer and winter diets of wolverines, Gulo gulo, in Arctic Alaska. - Canadian Field-Naturalist 101: 392-397.

Mattisson, J., Andrén, H., Persson, J. \& Segerström, P. 2011: Influence of intraguild interactions on resource use by wolverines and Eurasian lynx. - Journal of Mammalogy 92: 1321-1330.

May, R., van Dijk, J., Wabakken, P., Swenson, J., Linnell, J., Zimmermann, B., Odden, J., Pedersen, H., Andersen, R. \& Landa, A. 2008: Habitat differentiation within the large-carnivore community of Norway's multiple-use landscapes. - Journal of Applied Ecology 45: 13821391.

Myhre, R. \& Myrberget, S. 1975: Diet of wolverine (Gulo gulo) in Norway. - Journal of Mammalogy 56: 752-757.

Nagy, K. A. 1987: Field metabolic rate and food requirement scaling in mammals and birds. - Ecological Monographs 57: 111-128.

Pasitschniak-Arts, M. \& Larivière, S. 1995: Mammalian species Gulo gulo. - American Society of Mammalogist 499: $1-10$.

Pyke, G. H. 1984: Optimal foraging theory: a critical review. - Annual Review of Ecology, Evolution, and Systematics 15: 523-575.

Pyke, G. H., Pulliam, H. R. \& Charnov, R. L. 1977: Optimal foraging: a selective review of theory and tests. - Quarterly Review of Biology 52: 137-154.

Samelius, G., Alisauskas, R. T., Larivière, S., Bergman, C., Hendrickson, C. J., Phipps, K. \& Wood, C. 2002: Foraging behaviours of wolverines at a large arctic goose colony. - Arctic 55: 148-150.

Schoener, T. W. 1970: Nonsynchronous spatial overlap of lizards in patchy habitats. - Ecology 51: 408-418.

Smith, E. P. 1982: Niche breadth, resource availability, and inference. - Ecology 63: 1675-1681.

Sterck, E. H. M., Watts, D. P. \& van Schaik, C. P. 1997: The evolution of female social relationships in nonhuman primates. - Behavioral Ecology and Sociobiology 41: 291-309.

Teerink, B. J. 1991: Hair of West-European mammals. Cambridge University Press, Cambridge.

van Dijk, J., Andersen, T., May, R., Andersen, R. \& Landa, A. 2008a: Foraging strategies of wolverines within a predator guild. - Canadian Journal of Zoology 86: 966-975.

van Dijk, J., Gustavsen, L., Mysterud, A., May, R., Flagstad, $\varnothing$., Broseth, H., Andersen, R., Andersen, R., Steen, H. \& Landa, A. 2008b: Diet shift of a facultative scavenger, the wolverine, following recolonization of wolves. Journal of Animal Ecology 77: 1183-1190.

van Dijk, J., Hauge, K., Landa, A., Andersen, R. \& May, R. 2007: Evaluating scat analysis methods to assess wolverine Gulo gulo diet. - Wildlife Biology 13: 62-67.

White, K., Golden, H., Hundertmark, K. \& Lee, G. 2002: Predation by wolves, Canis lupus, on wolverines, Gulo gulo, and an American marten, Martes Americana, in Alaska. - Canadian Field-Naturalist 116: 132-134.

Whitman, J. S., Ballard, W. B. \& Gardner, C. L. 1986: Home range and habitat use by wolverines in southcentral Alaska. - Journal of Wildlife Management 50: 460-463.

Wikenros, C. 2011: The return of the wolf. Effects on prey, competitors and scavengers. - Ph.D. thesis, Swedish University of Agricultural Sciences.

Wikman M. (ed.) 2010: Riistakannat 2010. Riistaseurantojen tulokset. - Riista- ja kalatalouden tutkimuslaitos, selvityksiä 21/2010, Riista- ja kalatalouden tutkimuslaitos, Helsinki.

Wright, J. D. \& Ernst, J. 2004: Wolverine, Gulo gulo luscus, resting sites and caching behavior in the boreal forest. Canadian Field-Naturalist 118: 61-64. 